\title{
Home language and English language ability in South Africa: Insights from new data
}

\author{
Dorrit Posel and Jochen Zeller \\ (posel@ukzn.ac.za) (zeller@ukzn.ac.za) \\ University of KwaZulu-Natal \\ King George V Ave \\ Durban 4041
}

11 March 2010

\begin{abstract}
In this paper we analyse data on language ability collected in a new nationally representative household survey, the National Income Dynamics Study, which captures information on reading and writing ability, both in the individual's home language and in English. We find that self-assessed reading and writing ability are highly correlated in the data, and that individuals typically report considerably higher ability in their home language than in English. The data suggest large racial differences in language skills, in the individual's home language and particularly in English. Racial differences however are narrower among younger adults (aged 15 to 30 years) than among older adults.

Furthermore, whereas older women are less likely than older men to report being able to read and write very well, in both their home language and in English, this is reversed among younger women and men. Finally we show that individuals who report good reading and writing ability in their home language and far more likely to report good reading and writing ability in English.
\end{abstract}




\section{INTRODUCTION}

The 1990s witnessed a dramatic increase in the availability of socio-economic data in South Africa on the characteristics of individuals and the households in which they live. Since 1993, many household surveys have been conducted which collect detailed information on the demographic characteristics of South Africans, who they live with, their access to income and their expenditure patterns. However, there has been little focus on collecting information on the linguistic characteristics of individuals. South Africa is a multi-lingual society, with many South Africans being able to speak, read and write in more than one language, although at different levels of ability. The Population Censuses of 1996 and 2001, as well as some of the nationally representative household surveys that have been conducted since 1993, ask individuals to identify the "language most often spoken at home”. Some of the surveys also ask whether or not individuals can read and write in at least one (unspecified) language. However, no information is collected to distinguish linguistic ability in the individual's home language and in other languages.

In 2008, a new household survey was conducted, the National Income Dynamics Study (NIDS). This nationally representative survey collected socio-economic information on approximately 7,300 households (or 28,000 individuals), including information on how well individuals reported being able to read and write both in their home language and in English. In this study we evaluate and analyse these data.

In the next section, we discuss the various ways in which language ability is defined in the literature, we briefly review what data have been collected on language proficiency and literacy in South Africa and we outline broad findings from a range of studies undertaken. We then discuss how information on language ability has been collected in NIDS, highlighting concerns with the self-assessment of individual language skills. The focus of our study is on describing responses to home language and English language ability in the new survey, investigating the distribution of self-assessed language ability by race, age and 
gender, as well the relationship between reported ability in the individual's home language and in English.

\section{LANGUAGE PROFICIENCY IN SOUTH AFriCA}

There is no general, universally accepted definition of concepts such as "language proficiency", "language skills”, or "knowledge of language”. In theoretical linguistics, the latter term is usually understood as being synonymous with Chomsky's (1965) notion of linguistic competence. Linguistic competence is the native speaker's (tacit) knowledge of the grammar of his/her language, which allows the individual to produce and understand a theoretically unlimited number of sentences. Since humans are genetically predisposed to acquire language, Chomsky’s definition of linguistic competence implies that every (healthy) individual is fully competent in at least one language.

Hymes (1972) introduces the concept of communicative competence, which encompasses both linguistic competence in Chomsky's sense, but also a sociolinguistic dimension, i.e. the capacity for appropriate contextualised use of language in a particular discourse situation. The concept of communicative competence has played an important role in research on L2 acquisition and language teaching as well as in the development and use of language proficiency measures (cf. Canale \& Swain 1980, Bachman 1990).

Cummins (1979, 1980) distinguishes between two different kinds of language proficiencies, basic interpersonal communicative skills (BICS) and cognitive/academic language proficiency (CALP). While BICS include accent, oral fluency and sociolinguistic competence (and can therefore be considered as equivalent to the concept of communicative competence), CALP refers to the ability to understand and produce the more complex written and oral language of academic discourse. Cummins’s $(1979,1980)$ interdependence hypothesis argues that L1 and L2 CALP are closely related and that the development of CALP in a second language is in part determined by the speaker's level of CALP in the first language at the time when instruction in L2 begins. In later work, 
Cummins (2001) introduces a third type of language proficiency, discrete language skills, which encompass rule-governed aspects of language, such as phonological and grammatical knowledge, as well as basic (as opposed to advanced academic) reading and writing skills.

To the best of our knowledge, there are no studies in South Africa which offer national or nationally representative data on proficiency in more than one language. As noted in the introduction, the 1996 and 2001 Population Censuses, as well as some of the nationally representative household surveys conducted by Statistics South Africa, provide information about the language "most often" or "usually spoken at home”. Some of these surveys also collect information about self-assessed proficiency by asking individuals whether they can read, and whether they can write "in at least one language”. However, these questions do not specify the language in which the speaker is proficient, nor do they distinguish between different levels of proficiency. Furthermore, the surveys do not collect information on whether individuals are proficient in more than one language.

There are various studies in South Africa which examine language proficiency within smaller groups of speakers, but the results of these studies vary widely, depending on the size and composition of the sample, when and how the study was conducted, which data were available at the time, and what kind of language proficiency was assessed.

Webb (2002) discusses a study of the South African Broadcasting Corporation from the early 1990s, reported in van Vuuren \& Maree (1994), which distinguishes between four levels of proficiency ("no understanding”; “up to basic level”; "up to intermediate level”; "up to complex level”). Competency in a language was measured by assessing how well respondents were able to provide appropriate answers to three questions, whose proper understanding required different levels of proficiency. According to Webb (2002), the study finds that 47 percent of South Africans are proficient in English "up to a complex level”, while 31 percent have "no understanding” of English. However, Webb (2002: 79) notes a variety of problems with the SABC-study, of which the most serious is that it did 
not involve participants from rural communities. Consequently, its findings cannot be generalised to the population. Moreover, the study was conducted before the first democratic elections in 1994, and the results therefore do capture developments in the postapartheid period.

The Western Cape Language Audit 2001 (published in 2002) presents data on the language proficiency of senior officials and personnel of the Western Cape Provincial Administration and of the general public. The language proficiency of the Administration was measured on the basis of initial self-assessments, followed by checks carried out by fieldworkers. The audit finds that among employees in the Administration, "[a]t least two-thirds of Afrikaans and English-speakers can be regarded as fully adequate (proficient) in spoken Afrikaans and English” and that “[n]early 60\% of isiXhosa-speakers are proficient in English” (Western Cape Language Audit 2001 - 2002: 13). However, these findings are based on a highly selective sample, given that proficiency in two of the three official languages of the Western Cape (English, Afrikaans and Xhosa) is considered a job requirement in the Provincial Administration. For its findings regarding the general public, the Western Cape Language Audit distinguishes between three levels of proficiency, namely whether speakers are able (i) to understand, (ii) to read a newspaper article, or (iii) to explain a problem in a language. The audit reports that 80 percent of Xhosa-speakers can understand English and 20 percent can understand Afrikaans. Approximately 50 percent of Xhosaspeakers can explain a problem in English.

Deumert, Inder \& Maitra (2005) report the results of the Monash Survey of Internal Migration to Cape Town, conducted in 2004 in the Western Cape, which was based on interviews with 215 household heads and the evaluation of 754 questionnaires. The sample consisted of mainly Xhosa-speaking rural-urban migrants “with a high degree of social and economic deprivation” (Deumert, Inder \& Maitra 2005: 308). Among other things, participants in the study were asked to assess their proficiency in English according to six categories (“very high”, “high”, “average”, “low”, “very low”, “no knowledge”). The study found that the self-assessed proficiency of their participants was very high: 89.1 percent of 
adult household members reported that they can "speak" English, and more than 60 percent of the participants described their proficiency in English as "average” or higher. However, on the basis of conversations and interviews with some of the participants who classified their proficiency as "average” or "high”, Deumert, Inder \& Maitra (2005) conclude that self-assessed levels of proficiency are mostly over-estimated and that the language skills of those participants who report average or high proficiency in English are often less than basic. As a more realistic measure of proficiency, Deumert, Inder \& Maitra (2005: 310) quote the PanSALB sociolinguistic survey (2000), which reports that "more than $40 \%$ of people in South Africa often do not, or seldom, understand what is being communicated in English” (PanSALB 2000: 13).

Other studies of language proficiency in South Africa have focused specifically on literacy and academic proficiency levels. The 1996 LANGTAG (Language Plan Task Group) defines (functional) literacy as corresponding to Grade 7/Standard 5 level of schooling and accordingly puts the adult illiteracy rate in South Africa at 29 percent (Webb 2002: 90). Weideman \& van Rensburg (2002) discuss the results of the ELSA Plus test (English Language Skills Assessment for the tertiary environment) conducted by the Unit for the Development of Language Skills at the University of Pretoria. In 2002, when this test was applied to 1,098 first-year students in the Faculty of Humanities, 26 percent of the students were identified as having academic proficiency levels in English below Grade 10 (which is considered the minimum level required for successful education at a university).

Most studies therefore suggest that language proficiency and literacy skills, particularly in English, are low among South Africans. However, because of differences between the surveys regarding sample size, sample composition and type of language proficiency assessed, it is not possible to generalise the results to arrive at a representative conclusion for South Africa.

In the following sections, we evaluate and discuss data from the 2008 National Income Dynamics Study (NIDS), which provides information about South Africans' self-assessed 
reading and writing skills in their home language and in English. Since our main goal is to describe, rather than to interpret, this information with respect to demographic variables such as race, age and gender, we use the term "language ability” (which we regard as neutral with respect to the different types of language proficiencies discussed above) to refer to these self-assessed language skills. Only when we discuss the relationship between home language and English language ability do we use the term "language proficiency", which we then define as the self-assessed ability to both read and write "very well” in that language. We assume that this definition of proficiency captures at least those individuals with “discrete language skills” in Cummins’s (2001) terms, although the group of speakers who report being able to read and write very well in a language most certainly also includes individuals who are academically literate.

\section{INFORMATION ON LANGUAGE ABILITY COLLECTED IN THE NATIONAL INCOME DYNAMICS STUDY, 2008}

In 2008, a new nationally representative household survey for South Africa was conducted, the National Income Dynamics Survey (NIDS). NIDS is designed as a household panel survey which will track approximately 28,000 individuals in just over 7,300 households at two-year intervals. In 2009, the first wave of NIDS was released by the South African Labour and Development Research Unit.

In NIDS, as in the Population Census, individuals are asked to identify their home language, although the question is framed slightly differently: individuals are asked what language they "usually speak at home” rather than what language they "speak most often at home”. Table 1 describes home language reported in NIDS for all adults. The distribution of home language is comparable to that derived from the 2001 Population Census. Over 97 per cent of African adults (aged 15 years and older) report their home language as one of 
the nine official African languages. In contrast, among Coloured, Indian and White adults, 96 to 98 percent report their home language as being either Afrikaans or English. ${ }^{1}$

Table 1. Home language spoken among South Africans (15 years and older), 2008

\begin{tabular}{lcccc}
\hline & African & Coloured & Indian & White \\
\hline IsiNdebele & 1.7 & 0.2 & 0.1 & 0.0 \\
IsiXhosa & 22.8 & 0.9 & 0.9 & 0.0 \\
IsiZulu & 29.4 & 1.1 & 2.0 & 0.1 \\
Sepedi & 13.1 & 0.1 & 0.0 & 0.2 \\
Sesotho & 12.3 & 0.1 & 0.4 & 0.0 \\
Setswana & 9.6 & 0.6 & 0.0 & 0.7 \\
SiSwati & 3.0 & 0.0 & 0.0 & 0.0 \\
Tshivenda & 2.0 & 0.0 & 0.0 & 0.0 \\
Xitsonga & 3.9 & 0.0 & 0.0 & 0.0 \\
Afrikaans & 0.8 & 70.1 & 4.1 & 58.1 \\
English & 1.0 & 26.7 & 91.5 & 40.0 \\
Other & 0.6 & 0.2 & 1.1 & 0.9 \\
\hline Total & 100.0 & 100.0 & 100.0 & 100.0 \\
\hline \hline
\end{tabular}

Source: Own calculations, NIDS 2008

Note: The data have been weighted to represent population estimates.

A distinguishing characteristic of NIDS is that it is the first national survey also to capture information on language ability in reading and writing both in the individual's home language and in English. This information is collected only for adults (aged 15 years and older) who are resident members of a household. ${ }^{2}$ In the survey adults are asked to selfassess how well they can read and write in their home language and in English in two sets of questions. Response options are provided on a four-point scale of "very well”, “fair”, "not well” and "not at all” (questions H36 to H39 in the NIDS Adult Questionnaire).

\footnotetext{
${ }^{1}$ In the 2001 Population Census, almost 98 percent of African adults reported an African language as their home language and between 94 and 98 percent of Coloureds, Indians and Whites reported either English or Afrikaans as their home language (own calculations).

${ }^{2}$ Information in NIDS is collected separately for adults and for children. Questions on language ability were included only in the adult questionnaire.
} 


\section{DATA QUALIFICATIONS}

Many Indian adults surveyed in NIDS did not provide consistent responses to the initial question on which language “do you usually speak at home” (question B3 in the Adult Questionnaire), and the questions asked later in the survey on how well individuals could read and write in their "home language” and in English. The majority of Indians reported that they most often spoke English at home. However, their responses for their selfassessed ability in their home language and in English are not aligned. It appears that these Indian respondents interpreted their "home language” differently to the language they "usually speak at home", and in particular, it is likely that they interpreted their home language as their ancestral Indian language (e.g. Hindi, Tamil etc.). ${ }^{3}$ For purposes of consistency, we recoded the responses to home language ability to reflect the responses to English language ability among all Indians who reported English as their home language.

The key concern with the data collected on language ability in NIDS is that individuals are asked to self-assess their ability. Given the number of households surveyed, together with the wide range of areas covered in the NIDS questionnaire, the reliance on self-assessment (rather than on administered tests) is not surprising. However, several studies have documented that with self-assessment, individuals are likely to over-report their language ability, leading to an upward bias in the data (cf. de Bot 1992; Deumert, Inder \& Maitra 2005).

Levels of home language and English language ability therefore may be over-estimated in NIDS. Moreover, if English language proficiency conveys a certain social status, then overreporting may be high particularly in English language ability. It is also possible that individuals may assess their language ability relative to that of individuals in their community, leading to possible over-reporting particularly in communities in which levels

\footnotetext{
${ }^{3}$ This has also been observed in research by Broeder, Extra \& Maartens (2002: 18), who note that "many Indians [in South Africa], who are in fact first-language speakers of English and who have no proficiency in an Indian language, still view an Indian language as their 'mother tongue' or their 'first language'."
} 
of English language proficiency are generally low (see also Deumert, Inder \& Maitra 2005).

Notwithstanding these concerns, the data show consistency in individual responses across questions. As Table 2 below illustrates, there is a large overlap between self-assessed ability in reading and writing. Percentages in bold, reported in the diagonals of the table, identify the share of individuals who reported the same level of ability in writing as they did in reading. For example, 98 percent of all adults who reported being able to read very well in their home language also reported being able to write very well in their home language. As we would expect, the extent of the overlap is also greatest for the highest (very well) and lowest (not at all) categories of assessment.

Where self-assessed levels of reading and writing ability in English differ, adults are more likely to report lower levels of ability in writing than in reading. This can be identified by comparing the percentages to the right of the bold diagonals in Table 2 with those to the left. For example, among all adults who reported their reading ability in English as fair, 5.5 percent assessed their writing ability as being lower than fair, compared to 2.7 percent who reported a higher writing ability. This is not an unexpected result, given that it is generally easier to understand written text in a language in which one is not fully proficient than to produce writing in that language. In contrast, writing abilities are not reported as being less developed than reading abilities in the home language, and there are no large inconsistencies (for example, adults reporting either a very good reading ability and no writing ability, or conversely no reading ability and a very good writing ability). 
Table 2: The relationship between self-assessed ability in reading and writing

\begin{tabular}{|c|c|c|c|c|c|}
\hline & \multicolumn{5}{|c|}{ Writing in home language } \\
\hline $\begin{array}{l}\text { Reading in home } \\
\text { language }\end{array}$ & Very well & Fair & Not well & Not at all & Total \\
\hline Very well & 98.0 & 1.5 & 0.4 & 0.1 & 100.0 \\
\hline Fair & 7.4 & 87.4 & 3.9 & 1.3 & 100.0 \\
\hline Not well & 2.1 & 8.2 & 83.7 & 6.0 & 100.0 \\
\hline \multirow[t]{2}{*}{ Not at all } & 0.0 & 0.9 & 4.1 & 95.0 & 100.0 \\
\hline & \multicolumn{5}{|c|}{ Writing in English } \\
\hline Reading in English & Very well & Fair & Not well & Not at all & Total \\
\hline Very well & 96.3 & 3.1 & 0.6 & 0.1 & 100.0 \\
\hline Fair & 2.7 & 91.7 & 5.1 & 0.4 & 100.0 \\
\hline Not well & 0.2 & 3.8 & 90.5 & 5.6 & 100.0 \\
\hline Not at all & 0.1 & 0.3 & 1.8 & 97.8 & 100.0 \\
\hline
\end{tabular}

Source: Own calculations, NIDS 2008

Note: The data have been weighted to represent population estimates.

\section{SELF-ASSESSED READING AND WRITING ABILITY IN HOME LANGUAGE AND IN ENGLISH}

In Table 3, we describe population estimates, derived from NIDS 2008, of self-assessed ability in reading and writing in the individual's home language. The table shows that over 80 percent of adults, across all race groups, reported being able to read and to write in their home language at a level of "very well” or "fair”. To provide some basis for comparison with these data, we also report statistics in Table 4 which are generated from a nationally representative household survey conducted in 2007 (the Labour Force Survey 2007, September (LFS 2007:2)). This survey of approximately 30,000 households asked individuals, in two separate questions, whether or not they could read, and whether they could write, in at least one language (although not how well). The language is not specified in the questions, but it seems plausible that respondents would have reported on their reading and writing ability in their home language.

A comparison of Tables 3 and 4 shows that, if being able to read and write in a language corresponds to a self-assessed ability that is at least "fair", then the NIDS data are closely aligned to the literacy data captured in 2007. For example, in 2008, 82.4 percent of African 
adults assessed their reading ability as being fair or better. In the Labour Force Survey in 2007, 87.6 percent of African adults reported that they could read in a language. ${ }^{4}$ In fact, if literacy is defined as language ability which is self-assessed as being at least fair, then literacy levels are lower in NIDS than in the Labour Force Survey, and particularly among adults who are not White.

Table 3. Self-assessed reading and writing ability in home language among adults, 2008

\begin{tabular}{|c|c|c|c|c|c|}
\hline & African & Coloured & Indian & White & All adults \\
\hline & \multicolumn{5}{|c|}{ Reading ability } \\
\hline Very well & 61.9 & 69.0 & 82.0 & 95.0 & 66.4 \\
\hline Fair & 20.5 & 20.6 & 9.9 & 3.8 & 18.5 \\
\hline Not well & 8.6 & 5.0 & 4.6 & 0.5 & 7.4 \\
\hline Not at all & 9.0 & 5.4 & 3.5 & 0.7 & 7.7 \\
\hline \multirow[t]{2}{*}{ Total } & 100.0 & 100.0 & 100.0 & 100.0 & 100.0 \\
\hline & \multicolumn{5}{|c|}{ Writing ability } \\
\hline Very well & 62.4 & 67.2 & 82.0 & 94.8 & 66.7 \\
\hline Fair & 19.5 & 21.8 & 11.7 & 3.4 & 17.9 \\
\hline Not well & 8.6 & 5.3 & 2.6 & 1.5 & 7.4 \\
\hline Not at all & 9.5 & 5.7 & 3.7 & 0.2 & 8.0 \\
\hline Total & 100.0 & 100.0 & 100.0 & 100.0 & 100.0 \\
\hline
\end{tabular}

Source: Own calculations, NIDS 2008

Note: The data have been weighted to represent population estimates. Adults are aged 15 years and older.

Table 4. Reported literacy levels among adults, 2007

\begin{tabular}{lccccc}
\hline $\begin{array}{l}\text { Percentage who report } \\
\text { being able to: }\end{array}$ & African & Coloured & Indian & White & All adults \\
\hline Read & 87.6 & 93.0 & 98.5 & 99.4 & 89.5 \\
Write & 87.3 & 93.0 & 98.3 & 99.4 & 89.3 \\
\hline
\end{tabular}

Source: Own calculations, LFS 2007:2

Note: The data have been weighted to represent population estimates. Adults are aged 15 years and older.

In Table 5, we describe self-assessed English language ability among adults in NIDS. We would expect that across all race groups, a larger percentage would report a good ability in their home language than in English. This is the case for Africans, Coloureds and Whites,

\footnotetext{
${ }^{4}$ The percentages of all South Africans (including children) who reported being able to read and to write in at least one language are considerably lower than the percentages for adults specifically. In the LFS 2007:2, 71.7 percent and 71.6 percent of all South Africans reported being able to read and to write in at least one language respectively.
} 
for whom the majority do not report English as the language most often spoken at home. Among Indians, however, a slightly larger percentage assessed their English language abilities, in comparison to their home language abilities, as very well, even after the data reported in Tables 5 and 6 had been recoded to remove the observed inconsistencies regarding home language and English language ability discussed earlier. This is because there is a small group of Indians who reported an African language as the language usually spoken at home and who reported their English language ability as being higher than their home language ability. This highlights that in a multi-lingual society, the language an individual usually or most often speaks at home is not necessarily the individual's mother tongue.

A striking feature of the tables presented is the large racial gap in self-assessed language ability. African and Coloured adults are far less likely than Indian and White adults to assess their reading and writing abilities in their home language as being at least fair. The difference is even more pronounced for self-assessed English language ability. Whereas 42.3 and 48.4 percent of African and Coloured adults respectively reported being able to read very well in English, the corresponding percentages for Indian and White adults are 84.5 and 83.3 percent.

Table 5. Self-assessed reading and writing ability in English among adults, 2008

\begin{tabular}{lccccc}
\hline & African & Coloured & Indian & White & All adults \\
\hline \multicolumn{5}{c}{} & \multicolumn{5}{c}{ Reading ability } \\
\hline Very well & 42.3 & 48.4 & 84.5 & 83.3 & 48.2 \\
Fair & 25.8 & 24.8 & 9.0 & 13.7 & 24.0 \\
Not well & 14.2 & 16.1 & 2.2 & 1.8 & 12.8 \\
Not at all & 17.7 & 10.7 & 4.3 & 1.2 & 15.0 \\
\hline Total & 100.0 & 100.0 & 100.0 & 100.0 & 100.0 \\
\hline \multicolumn{5}{c}{ Writing ability } \\
\hline Very well & 41.3 & 47.7 & 84.4 & 81.0 & 47.1 \\
Fair & 25.6 & 25.0 & 9.6 & 15.1 & 24.0 \\
Not well & 14.8 & 16.3 & 1.5 & 2.7 & 13.4 \\
Not at all & 18.3 & 11.0 & 4.5 & 1.2 & 15.5 \\
\hline Total & 100.0 & 100.0 & 100.0 & 100.0 \\
\hline \hline Source: Own calculations, NIDS 2008 & \multicolumn{5}{c}{} \\
Note: The data have been weighted to represent population estimates. Adults are aged 15 years and older.
\end{tabular}


Differences across race, however, are considerably narrower among a younger age cohort than an older cohort. We illustrate this in Figures 1 and 2, which compare reported ability in reading in the home language among younger adults, aged 15 to 30 years, and among adults older than 30 years. The gap in reading very well among younger African and White adults is less than 20 percentage points, whereas it is almost 40 percentage points among older adults.

Figure 1: Self-assess ed reading ability in home language, adults aged 15 to 30,2008

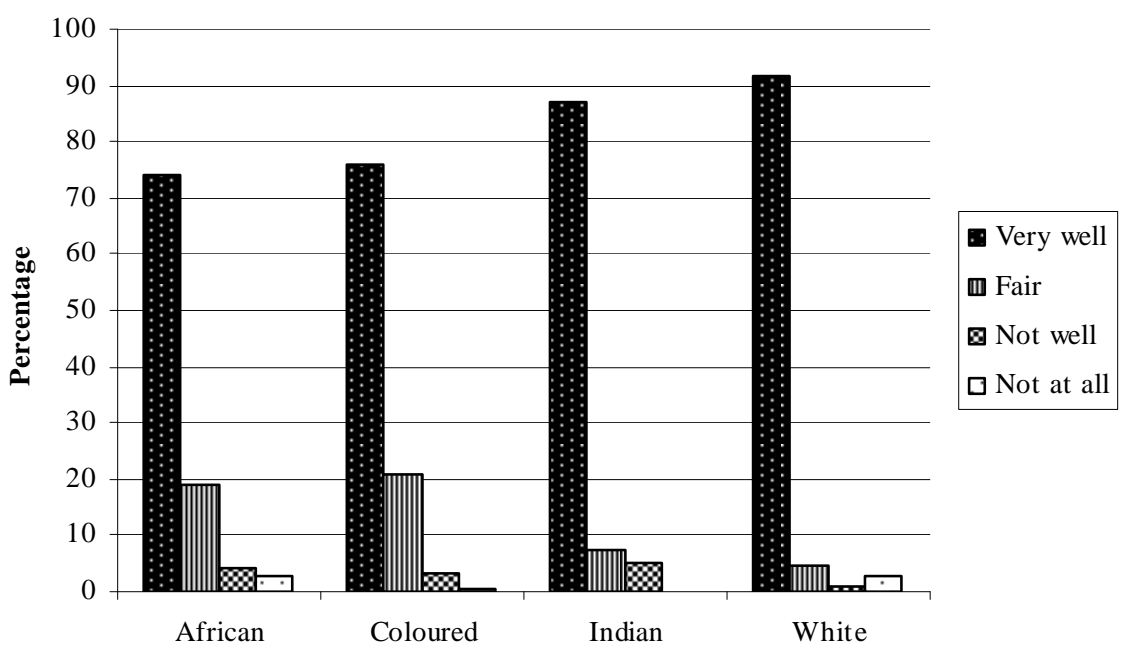

Source: Own calculations, NIDS 2008

Note: The data have been weighted to represent population estimates. 
Figure 2: Self-assessed reading ability in home language, adults older than 30,2008

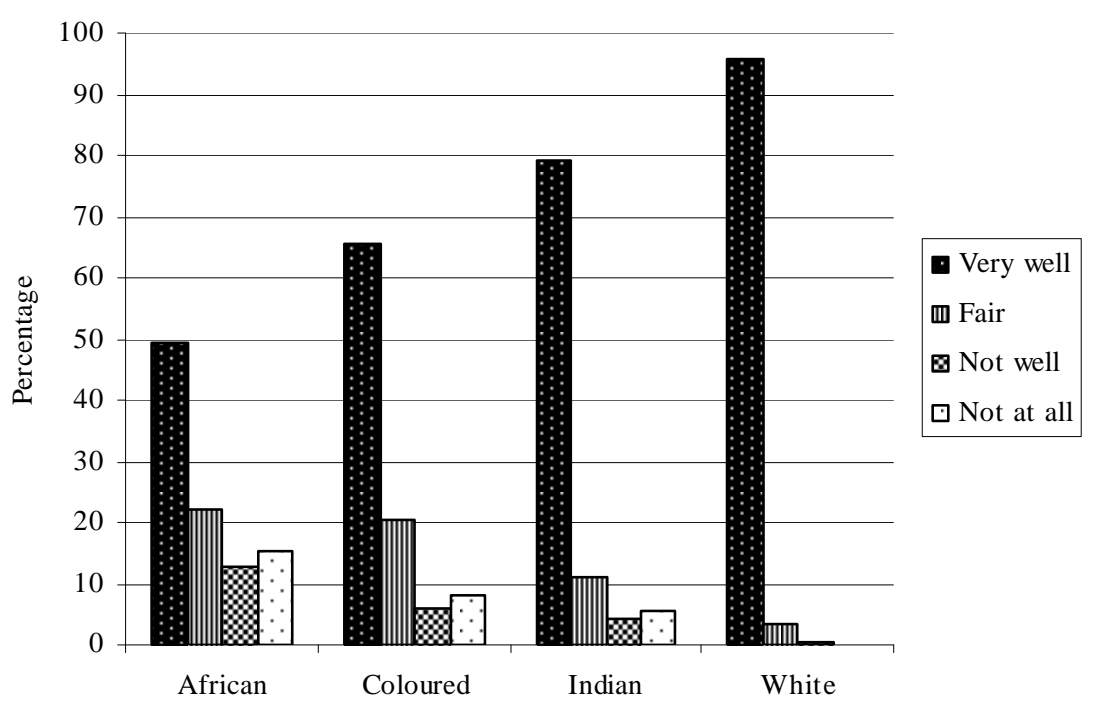

Source: Own calculations, NIDS 2008

Note: The data have been weighted to represent population estimates.

For all race groups except Whites, home language reading ability is reported as being higher among younger cohorts than among older cohorts. Among Whites, however, a slightly larger proportion of adults older than 30 reported being able to read in their home language "very well", compared to adults aged 15 to 30 years.

Differences in home language ability by age cohort are largest among Africans, a pattern which is mirrored in results for English language ability. Figure 3 illustrates that African adults aged 15 to 30 years are almost twice as likely as older African adults to report reading very well in English; and whereas only five percent of young adults reported not being able to read in English at all, almost 31 percent of older adults reported no ability to read English. These differences may reflect a systematic bias in reporting by age cohort, where younger cohorts are more likely than older cohorts to over-report their language ability. However, the data would also be consistent with socio-economic changes since the ending of apartheid. 
Figure 3: Reading ability in English among African adults (15 years and older), 2008

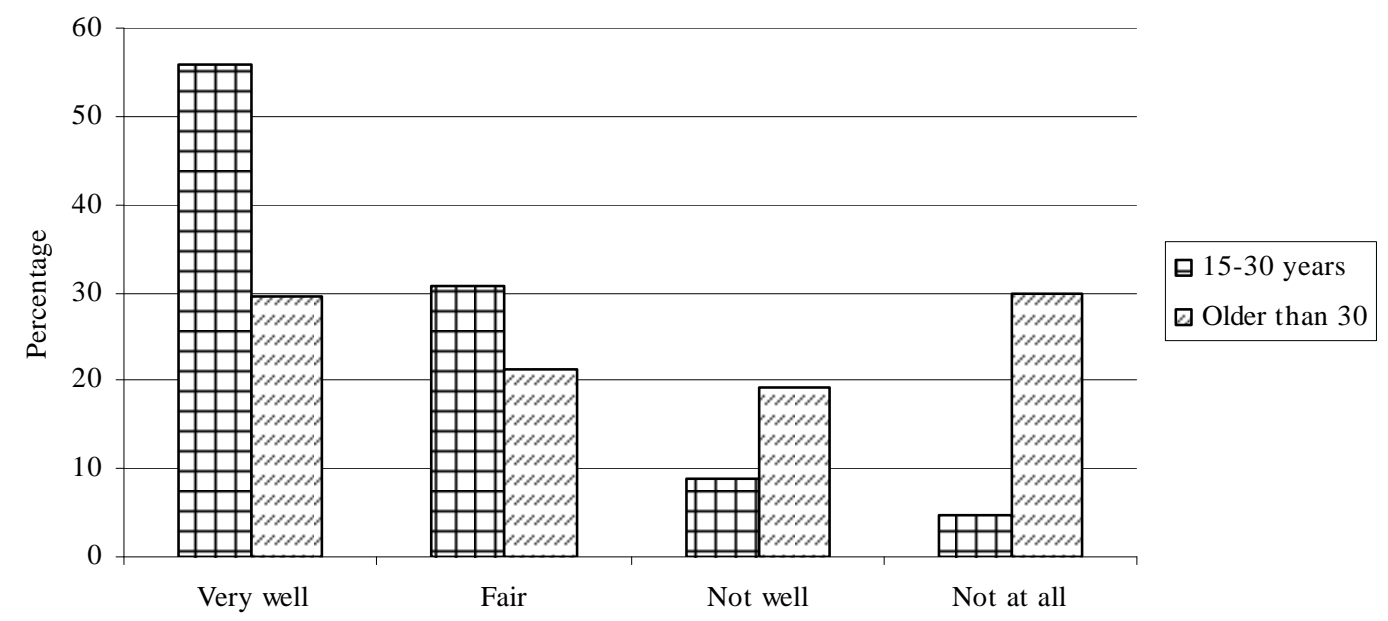

Source: Own calculations, NIDS 2008

Note: The data have been weighted to represent population estimates.

The NIDS data also suggest interesting differences in home and English language ability by gender and age cohort. Although a gender gap in self-assessed language ability remains among older men and women, younger women assess their language ability as being higher than younger men. This is illustrated in Table 6, which compares reading ability in home language and in English among younger men and women, and among older men and women. For all adults aged 15 to 30, a larger proportion of women than men assessed that they could read "very well" in their home language. For example, whereas 80 percent of young Coloured women reported that they could read very well in their home language, only 70 percent of young Coloured men provided the same assessment. Among older adults, however, this pattern is reversed, particularly among Africans and Indians. It seems very unlikely that younger women are systematically more likely than younger men to over-estimate their language ability, while the reverse would hold true for older men and women. Rather, the data point to progress in redressing gender inequalities and increasing opportunities for women in education in recent decades. 
There is mostly a similar set of patterns for English language ability, reported in Table 7. Young women are more likely than young men to assess their reading ability in English as high, whereas the opposite appears for older women and men. For example, 59 percent of young African women reported that they could read very well in English compared to 52 percent of young African men. In contrast, 53 percent of older African men and 47 percent of older African women assessed their reading ability in English as being high.

Table 6. Self-assessed reading ability in home language by gender, 2008

\begin{tabular}{|c|c|c|c|c|c|c|c|c|}
\hline & \multicolumn{2}{|c|}{ African } & \multicolumn{2}{|c|}{ Coloured } & \multicolumn{2}{|c|}{ Indian } & \multicolumn{2}{|c|}{ White } \\
\hline & Men & Women & Men & Women & Men & Women & Men & Women \\
\hline & \multicolumn{8}{|c|}{ Adults aged 15 to 30} \\
\hline Very well & 74.3 & 75.7 & 69.9 & 80.0 & 84.0 & 90.0 & 84.8 & 97.0 \\
\hline Fair & 18.9 & 18.7 & 25.0 & 17.7 & 16.0 & 0.3 & 8.8 & 1.3 \\
\hline Not well & 4.3 & 3.7 & 4.7 & 1.9 & 0.0 & 9.7 & 1.3 & 0.8 \\
\hline \multirow[t]{3}{*}{ Not at all } & 2.5 & 1.9 & 0.4 & 0.4 & 0.0 & 0.0 & 5.1 & 0.8 \\
\hline & 100.0 & 100.0 & 100.0 & 100.0 & 100.0 & 100.0 & 100.0 & 100.0 \\
\hline & \multicolumn{8}{|c|}{ Adults older than 30} \\
\hline Very well & 53.2 & 46.9 & 65.6 & 65.2 & 83.2 & 75.7 & 96.6 & 95.4 \\
\hline Fair & 21.2 & 22.7 & 21.5 & 19.8 & 13.2 & 9.7 & 3.4 & 3.7 \\
\hline Not well & 12.1 & 13.4 & 5.7 & 6.4 & 2.4 & 5.6 & 0.0 & 0.6 \\
\hline Not at all & 13.4 & 16.9 & 7.2 & 8.6 & 1.2 & 9.0 & 0.0 & 0.3 \\
\hline & 100.0 & 100.0 & 100.0 & 100.0 & 100.0 & 100.0 & 100.0 & 100.0 \\
\hline
\end{tabular}

Source: Own calculations, NIDS 2008

Note: The data have been weighted to represent population estimates

Table 7. Self-assessed reading ability in English by gender, 2008

\begin{tabular}{|c|c|c|c|c|c|c|c|c|}
\hline & \multicolumn{2}{|c|}{ African } & \multicolumn{2}{|c|}{ Coloured } & \multicolumn{2}{|c|}{ Indian } & \multicolumn{2}{|c|}{ White } \\
\hline & Men & Women & Men & Women & Men & Women & Men & Women \\
\hline & \multicolumn{8}{|c|}{ Adults aged 15 to 30} \\
\hline Very well & 52.0 & 59.4 & 54.9 & 53.6 & 84.0 & 96.7 & 72.5 & 85.8 \\
\hline Fair & 32.4 & 28.9 & 30.5 & 32.4 & 16.0 & 0.0 & 20.4 & 13.4 \\
\hline Not well & 9.4 & 8.3 & 11.4 & 11.7 & 0.0 & 3.3 & 2.3 & 0.0 \\
\hline \multirow[t]{3}{*}{ Not at all } & 6.2 & 3.3 & 3.2 & 2.3 & 0.0 & 0.0 & 4.8 & 0.8 \\
\hline & 100.0 & 100.0 & 100.0 & 100.0 & 100.0 & 100.0 & 100.0 & 100.0 \\
\hline & \multicolumn{8}{|c|}{ Adults older than 30} \\
\hline Very well & 53.2 & 46.9 & 65.6 & 65.2 & 83.2 & 75.7 & 96.6 & 95.4 \\
\hline Fair & 21.2 & 22.7 & 21.5 & 19.8 & 13.2 & 9.7 & 3.4 & 3.7 \\
\hline Not well & 12.1 & 13.4 & 5.7 & 6.4 & 2.4 & 5.6 & 0.0 & 0.6 \\
\hline Not at all & 13.4 & 16.9 & 7.3 & 8.6 & 1.2 & 9.0 & 0.0 & 0.3 \\
\hline & 100.0 & 100.0 & 100.0 & 100.0 & 100.0 & 100.0 & 100.0 & 100.0 \\
\hline
\end{tabular}

Source: Own calculations, NIDS 2008

Note: The data have been weighted to represent population estimates. 


\section{THE RELATIONSHIP BETWEEN HOME LANGUAGE AND ENGLISH LANGUAGE ABILITY}

In a final set of tabulations, we compare the relationship between home language and English language ability. This relationship has particular resonance in the context of language policy in education in South Africa. The post-apartheid government has adopted what is viewed to be a progressive Language-in-Education Policy (LiEP), which allows individual schools (through the School Governing Bodies) to decide on the language of learning and teaching (Probyn et al 2002; Webb 2002; Brock-Utne \& Holmarsdottir 2004). The policy encourages (but does not require) schools to maintain the learners' home language at the same time as they learn an additional language. This approach is based on the concept of additive bilingualism, developed in theories of second language acquisition, which suggest that the best way for learners to gain an understanding of concepts generally and second language skills in particular is through a thorough grounding in the learner's home language, alongside learning in English (cf. Cummins 1980; Thomas \& Collins 1997; Heugh 1999; Probyn et al 2002; Brock-Utne \& Holmarsdottir 2004). African mothertongue education in South Africa, however, has been tainted by its association with the repressive policies of apartheid. Consequently, many schools in which the majority of learners are African home language or mother-tongue speakers have maintained the use of English as the language of learning and teaching from at least Grade 4.

To explore the relationship between home language and English language ability, we combine information on reading and writing ability to generate a binary variable which captures language proficiency. Because of concerns with over-reporting, we define an individual as being language "proficient" only if they report being able to both read and write very well in the language. Table 8 reports home language and English language proficiency among all adults, and by race. Based on our definition of proficiency, the NIDS data suggest that approximately 65 percent of adults in South Africa are home language proficient whereas only 47 percent are English language proficient. Both home language and English language proficiency are lowest among African adults. 
Table 8. Home language and English language proficiency among adults, 2008

\begin{tabular}{|c|c|c|c|c|c|}
\hline $\begin{array}{l}\text { Percentage } \\
\text { who are: }\end{array}$ & African & Coloured & Indian & White & All adults \\
\hline $\begin{array}{l}\text { Home } \\
\text { language } \\
\text { proficient }\end{array}$ & 60.7 & 66.5 & 82.0 & 94.2 & 65.2 \\
\hline $\begin{array}{l}\text { English } \\
\text { language } \\
\text { proficient }\end{array}$ & 40.6 & 47.0 & 84.4 & 80.7 & 46.6 \\
\hline
\end{tabular}

In Figure 4 we compare English language proficiency among African adults according to whether or not they are identified as being proficient in their home language. The figure shows that individuals are far more likely to be identified as English language proficient if they are also proficient in their home language. Among African adults who report that they can read and write very well in their home language, over 60 percent also report reading and writing very well in English. In contrast, among those who are not identified as home language proficient, only 8 percent report both reading and writing very well in English. The finding that home language proficiency is strongly related to English language proficiency is consistent with the arguments of additive bilingualism, and warrants investigation in future analysis of the data. 
Figure 4: English language proficency by home language proficiency, African adults 2008

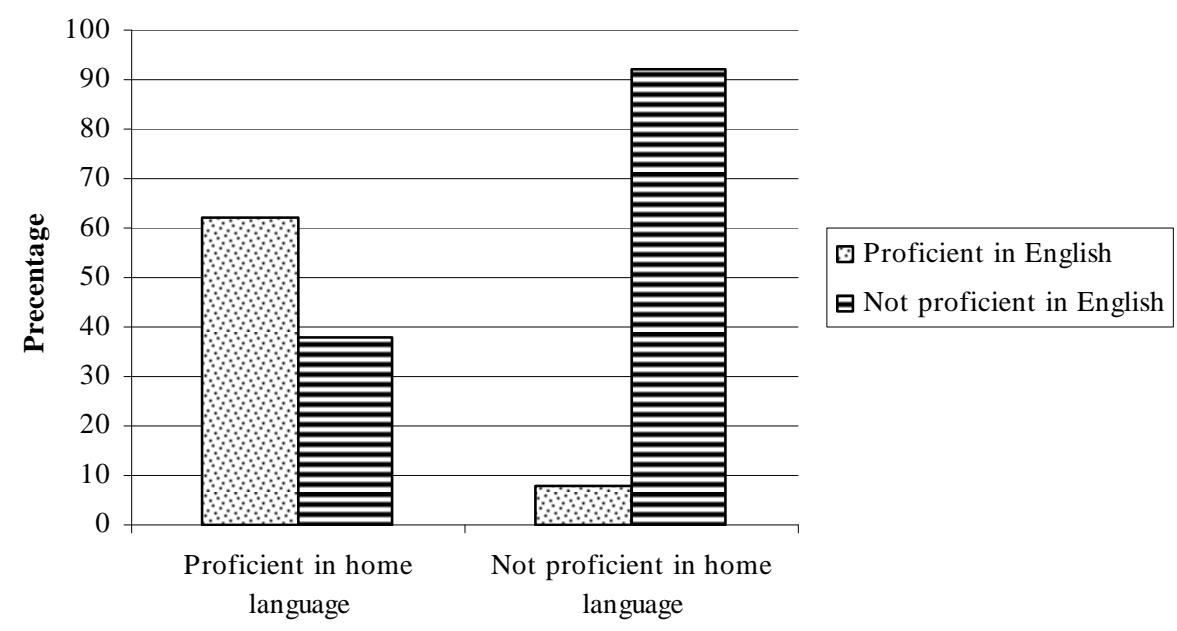

Source: Own calculations, NIDS 2008.

Note: Proficiency is defined as the self-assessed ability to both read and write very well in the language.

\section{CONCLUSION}

The analysis of the NIDS household survey data presented in this paper suggests that approximately 65 percent of all South Africans, and almost 61 percent of all Africans, are proficient (can read and write "very well”) in their home language. The corresponding percentages for English language proficiency are approximately 47 percent of all South Africans, and 41 percent of all Africans. Our findings therefore fall within the range of results of smaller and more regionally specific studies regarding functional literacy and English language proficiency in South Africa. The NIDS data also display consistent patterns in the reporting on reading and writing ability. Furthermore, the data produce sensible distributions of home language and English language ability across race and other demographic groups, distributions that would be expected given the nature of South Africa's history. We believe therefore that the data in NIDS provide a useful resource for describing relative differences in language ability in the country. Nonetheless, we acknowledge that individuals are likely to over-report or over-estimate their language 
ability. The inclusion of a regular language proficiency test in a subsequent wave of the NIDS survey, alongside questions of self-assessed language ability, would make it possible to explore more comprehensively the extent and distribution of over-reporting on language ability.

\section{REFERENCES}

Bachman, L. 1990. Fundamental Considerations in Language Testing. Oxford: Oxford University Press.

Brock-Utne, B. and Holmarsdottir, H.B. 2004. Language policies and practices in Tanzania and South Africa: problems and challenges. International Journal of Educational Development 24: 67 - 83.

Broeder, P., Extra, G. and Maartens, J. 2002. Multilingualism in South. Africa with a focus on KwaZulu-Natal and Metropolitan Durban. Praesa Occasional Paper 7.

Canale, M. and Swain, M. 1980. Theoretical bases of communicative approaches to second language teaching and testing. Applied Linguistics 1, 1-47.

Chomsky, N. 1965. Aspects of the Theory of Syntax. Cambridge: MIT Press.

Cummins, J. 1979. Cognitive/academic language proficiency, linguistic interdependence, the optimum age question and some other matters. Working Papers on Bilingualism 19, 121-129.

Cummins J. 1980. The Cross-Lingual Dimensions of Language Proficiency: Implications for Bilingual Education and the Optimal Age Issue. TESOL Quarterly 14 (2), 175-187. 
Cummins, J. 2001. Negotiating Identities: Education for empowerment in a diverse society. $\left(2^{\text {nd }}\right.$ ed.) Los Angeles: California Association for Bilingual Education.

de Bot, K. 1992. Self-Assessment of Minority Language Proficiency. In: L. Verhoeven and J. H.A.L. De Jong (eds), The Construct of Language Proficiency. Amsterdam: John Benjamins, 137-146.

Deumert, A., Inder, B. and Maitra, P. 2005. Language, Informal Networks and Social Protection: Evidence from a Sample of Migrants in Cape Town, South Africa. Global Social Policy 5(3), 303-328.

Heugh, K. 1999. Languages, development and reconstructing development in South Africa. International Journal of Educational Development 19, 301 - 313.

Hymes, D. 1972. On communicative competence. In: J. B. Pride and J. Holmes (eds.): Sociolinguistics. Harmondsworth: Penguin Education, 269-293.

Langtag report 1996. Towards a National Language Plan for South Africa. Final Report of the Language Plan Task Group. Pretoria: Department of Arts, Science, Culture and Technology.

PanSALB (2000). Language Use and Language Interaction in South Africa: A National Sociolinguistic Survey. Pretoria: PanSALB.

Probyn, M., Murray, S., Botha, L., Botya, P., Brooks, M. and Westphal, V. 2002. Minding the gaps - an investigation into language policy and practice in four Eastern Cape districts. Perspectives in Education 20(1), 29 - 46. 
Thomas, W. and Collier, V. 1997. School Effectiveness for Language Minority Students. National Clearinghouse for Bilingual Education (NCBE) Resource Collection Series No. 9.

van Vuuren, D.P. and Maree, A. 1994. Report: Language and broadcasting in South Africa. A research perspective. Broadcasting Research Unit. SABC.

Webb, V. 2002. Language in South Africa. The role of language in national transformation, reconstruction and development. Amsterdam/New York: John Benjamins.

Weideman, A. and van Rensburg, C. 2002. Language proficiency: Current strategies, future remedies. Journal for Language Teaching 36 (1\&2), 152-164.

Western Cape Language Audit 2001 (2002). http://www.capegateway.gov.za /Text/2004/1/02e-western_cape_lang_audit_2001.pdf. (last accessed 11.3.2010). 